\title{
Steady and delayed: Explaining the different development of meta- ethnography in health care and education
}

I. Uny ${ }^{1}$, E.F. France ${ }^{1}$, G.W. Noblit ${ }^{2}$

1. Nursing Midwifery and Allied Health Professions Research Unit, University of Stirling, Stirling, Scotland, UK.

2. School of Education, The University of North Carolina at Chapel Hill, North Carolina, USA.

Correspondence: Isabelle.uny@stir.ac.uk

Nursing Midwifery and Allied Health Professions Research Unit, University of Stirling, Unit 13 Scion House, Stirling University Innovation Park, Stirling FK9 4NF, Scotland, UK 


\section{Steady and delayed: explaining the different development of meta- ethnography in health care and education}

Since its inception in the 1980s, the meta-ethnography approach for synthesising qualitative study accounts has been used extensively in health and social care research and to a lesser extent in educational research. The aim of this article is to reflect on the evolution of the method in both fields. It starts by describing the meta-ethnography approach, charts the rise of evidence-based research in healthrelated research, and explores the growth in the rate of published health-related meta-ethnographies. It proceeds by offering some explanation for the slower growth in the use of meta-ethnography in educational research. It explains this using the history of the early developments of qualitative approaches in Education and their underpinning paradigms. It then discusses key meta-ethnographies conducted in education, comparing those to more recent ones, in terms of methodological development. The article concludes by drawing lessons about how the conduct of meta-ethnography may be improved in any discipline.

Keywords: meta-ethnography; qualitative evidence synthesis; health; education; systematic reviewing; qualitative approach; 
Meta-ethnography was originally developed in the 1980s in education research by Noblit and Hare (1988). Both were educational researchers and social scientists and developed the methodology whilst conducting a review of school desegregation in the United States, as a means to unravel meaning about the "social institution of education" (14). Metaethnography is one of the earliest approaches developed for synthesising primary qualitative research studies. Whereas some qualitative synthesis approaches are aggregative in nature, meta-ethnography is an interpretive approach where the aim is not merely to summarise evidence on a topic of interest, but to arrive at new interpretations of that topic. Since its inception in the 1980s, the meta-ethnographic approach has been used extensively in health-related and social care research (Dixon-Woods, Booth, and Sutton 2007; Hannes and Macaitis 2012; France et al. 2014) but its use has been less prolific in the field of education research (Thorne et al. 2004). One of the aims of this article is to reflect on how meta-ethnography has been used in health-related research compared to its use in the field of education, and to reflect on ongoing debates and issues surrounding the conduct and the reporting of the meta-ethnography approach. To that effect, we first briefly describe the meta-ethnography approach. We then chart the rise of evidence-based research and of qualitative data as evidence in health-related research and the steady growth in the rate of published meta-ethnographies in that field, paying particular attention to the methodological contribution of the most seminal ones. The article then reflect on the delayed growth of the use of meta-ethnography in education research, and offers methodological insights on its development as an approach in that field. This is done by looking in details at some of the most important meta-ethnographies conducted in the last two decades. The article concludes by drawing lessons for the conduct and reporting of meta-ethnographies which apply both to the health and education research fields, as well as potentially to other disciplines. 


\section{What is meta-ethnography?}

Meta-ethnography is an inductive, interpretive synthesis approach carried out through seven phases summarised in the figure below.

[Figure 1. The seven phases of Noblit and Hare's meta-ethnography approach near here]

The seven phases described above were not meant by Noblit and Hare (Noblit and Hare 1988) to be used as a rigid framework, or a set of mechanistic tasks. In fact, in practice, some phases tend to overlap or to take place in parallel (for example phases 4 and 5). What renders meta-ethnography unique, according to Noblit and Hare, is not the use of those seven phases, but rather the use of a process of translation to arrive at the synthesis, as well as the fact that the methodology is rooted in Turner's theory of a "social explanation based in comparative understanding rather than in aggregation of data" (23). There are three main components of the theory of social explanation: first, it is comparative in nature (e.g. the researcher compares data to their own experience or hypotheses, or compares sets of data with each other). Secondly, out of this comparative process comes an interrogation about how the different contexts (whether social, economic, or historical), values, norms and social structures may impact on any social explanation of a phenomenon. What takes place is a process of translation, by which the researcher translates other researchers' practices into their own, or the interpretations (concepts, metaphors) contained in one qualitative study into the others. This translation is not literal, but rather idiomatic- in the sense that it translates concepts into other concepts-, it is the translation of one account into another which forms the final 
synthesis. Meta-ethnography thus uses translation to arrive at new meanings and interpretations of a particular social phenomenon or topic. The third key component of the theory of social explanation is that it is inductive, and grounded in the data being compared (in this case the primary studies to be synthesised in the meta-ethnography); this means, as Noblit and Hare stated that: "each researcher will have different substantive interests, see different comparative puzzles, and achieve different syntheses" $(1988,32)$. Although Noblit and Hare saw this theory of social explanation as particularly suitable for the synthesis of the ethnographies they were concerned with at the time, meta-ethnography has been used since to synthesise data from many different types of qualitative studies. These have included, for example, studies with very different epistemologies (e.g.Pound et al. 2005), studies using a range of qualitative data collection methods including narrative case studies and semi-structured interviews (e.g.Soundy et al. 2013), and even studies using a variety of primary research accounts including autobiographical books (e.g.Page and Keady 2010).

Over the last two decades, the meta-ethnographic approach has gained increasing popularity in health-related research particularly as a means to synthesise the growing qualitative evidence on health, illness, and patients' experiences. Although it is not the only qualitative synthesis approach to permeate health research, it is now reportedly the most used (Hannes and Macaitis 2012), and most other, newer, qualitative evidence synthesis approaches are indeed based on it, which demonstrates its influence (DixonWoods, Booth, and Sutton 2007; Campbell et al. 2011; Thorne et al. 2004). For instance, meta-study (Paterson 2011) incorporates meta-ethnography but goes beyond it to give further attention to the "creative interpretation of the primary research to produce new and expanded understandings of the phenomenon under study" (Campbell et al. 2011, 
20). Another method, critical interpretive synthesis (Dixon-Woods et al. 2006), has built also on meta-ethnography to integrate, qualitative, quantitative, and mixed-methods studies into syntheses. Meta-interpretation - an interpretive method of qualitative evidence synthesis developed initially by Finfgeld (1999) has also been guided by metaethnography and grounded theory.

\section{The rise of evidence-based health-care research and of qualitative data as evidence}

To understand the rise in popularity of meta-ethnography (and indeed of other qualitative evidence synthesis approaches), it is necessary to understand how qualitative research has gradually come to be accepted as part of the evidence base for health care policy and practice. The idea of synthesising evidence to provide up to date, reliable, information which can be used to design interventions is not entirely novel. In the 1970s and 1980s, some quantitative meta-analyses had been conducted in the fields of oncology and perinatal care already (Volmink et al. 2004). However in 1972, Archie Cochrane, a medical doctor, published a key book entitled Effectiveness and Efficiency: Random Rejections on Health Services (Cochrane 1972 ). In this publication he argued that, given the fact that resources for health may always be finite, they ought to be used to fund health care which had been proven to be effective. He argued particularly for the use of evidence from randomized controlled trials (RCT's) ${ }^{1}$ which were seen to be

\footnotetext{
${ }^{1}$ A randomised controlled trial (RCT) is defined as 'An experiment in which two or more interventions, possibly including a control intervention or no intervention, are compared by being randomly allocated to participants. In most trials one intervention is assigned to each individual but sometimes assignment is to defined groups of individuals (for example, in a household) or interventions are assigned within
} 
based on scientific evidence. This paved the way for the future use of systematic reviews, pioneered by Chalmers and colleagues at the UK National Perinatal Epidemiology Unit, and their attempt in 1978 to collate a vast amount of evidence from controlled trials in perinatal medicine, which led ultimately to an international collaboration and two large publications on Effective care in Pregnancy and Childbirth (Volmink et al. 2004). The term 'systematic review', refers to "a review of a clearly formulated question that uses systematic and explicit methods to identify, select and critically appraise relevant research, and to collect and analyse data from the studies that are included in the review" (779). Originally, systematic reviews were undertaken primarily to show whether interventions or particular medical treatments were effective, and whether certain diagnostic tests were accurate.

One key example of the importance of systematic reviews is that of a review of RCTs on short-term and low-cost corticosteroids to be administered to pregnant women likely to deliver ahead of their due date. This was a treatment which had been thought to reduce the risk of death of premature babies by 30 to $50 \%$. However because no systematic review of those particular RCTs had been published until 1989, many health professionals were unaware that this simple intervention was effective, and therefore did not apply it routinely, which means that for decades many babies died needlessly. It is to prevent this kind of tragedy, that from the efforts of Cochrane and Chalmers, Cochrane, as an organisation, was created in 1993 (Chalmers 1993), as a repository where systematic reviews could be registered and easily accessed.

individuals (for example, in different orders or to different parts of the body)' ( Source: http://communityarchive.cochrane.org/glossary/5\#term372 ) 
By the late 1990s those systematic reviews had established themselves in health-related research, as the most scientific method to collate evidence from quantitative studies. What is meant by 'scientific' here is that they were considered to use rigorous and transparent methods which paid attention to the quality of the studies reviewed, and also that they were heavily peer-reviewed. Systematic reviews were also supposed to be replicable and updateable, and presented in a manner which made them both relevant and useful to practitioners and policy-makers. In fact, Cochrane reviews have been used in health for over a decade to inform healthcare standards and practices. Within that time, some concern had been expressed at the fact that some types of evidence in health care (such as RCTs) had been given more weight than others, particularly those coming from research based on patients' interviews, or service users' narratives. As Campbell et al (2011) explain "interest was beginning to shift towards how qualitative data could be brought into the evidence base and a 'science of Synthesis' developed for qualitative research" (2), led by the National Institute of Health Research's Health Technology Assessment (HTA) methodology programme. Because of such shifts, the Cochrane Qualitative Research Methods Group was established in 2004 to offer policy advice and recommendations on how to incorporate qualitative evidence within systematic reviews (Booth 2001).

This shift towards the acceptance of qualitative data as evidence happened in other fields as well. Indeed in countries such as the UK, there has been a strong push towards more evidence-based policymaking in the education sector in recent years. This can be seen in the setting up of the Centre for Evidence-informed Policy and Practice in Education (EPPI-Centre) in 2001, and the creation of the Campbell Collaboration in 2000, which 
aims to provide systematic reviews on the effectiveness of social interventions in criminal justice, education, and social care, and which includes qualitative data. However the adaptation of the medical model of systematic reviews to educational research has been described by some authors as problematic (Evans and Benefield 2001). Though it is not entirely clear why this is the case, some of the reasons offered concern the difficulty formulating questions with clear boundaries such as those suited to quantitative systematic reviews, and the difficulty met in identifying and appraising studies which borrow at once from the fields of sociological, psychological and educational research (Evans and Benefield 2001; Andrews 2005)

There has been a recognition in the last two decades that the evidence produced by systematic reviews on its own may not be sufficient to inform policy and practice, or may not give the full picture Although, on the one hand, health care intervention effectiveness does need to be determined, on the other hand, there is also a need to hear patients' perspectives and to understand their attitudes if we are to improve health services and patients' experiences. Understanding how patients perceive their own illness or why they may or may not choose to adhere to certain treatments may be key in designing more acceptable and more effective interventions. This type of evidence is usually found in qualitative studies, and this has led to greater demand for the development of methods which can combine, compare and interpret bodies of qualitative studies, methods which the Cochrane Qualitative Research Methods Group calls qualitative evidence syntheses (QES). Today, qualitative evidence synthesis approaches, in health research as in other fields, are seen as methodologies which can enhance knowledge and scope about particular topics, help reach further generalizability about them, or as the case may be, help challenge existing views about them (Paterson 2011). However systematic review 
processes do not necessarily suit the conduct of QES such as meta-ethnography. For instance, in systematic reviews of quantitative studies it is recommended to conduct exhaustive searches of the literature in order to avoid bias in the studies which are included, and to enhance transparency and enable replicability. In QES, however, the search methodology has to be the one that best suits the purpose of the synthesis and is most likely to identify relevant research. Exhaustive searching may be suitable if the goal is to make more generalizable claims or to provide a comprehensive picture of research in an area. Whereas expansive, non-linear searching might be appropriate for interpretive qualitative syntheses which intend to generate theory (Finfgeld-Connett and Johnson 2013; France et al. 2014). Although systematic reviews have remained very popular in the field of health research, their use has been seen as more controversial in other disciplines. In education research, for instance, the use of systematic reviews has been criticised by some for being too positivist in nature (Andrews 2005; Van Klaveren and De Wolf 2013), too much in the pursuit of hard facts, rather than in the pursuit of new interpretations. Yet it is meta-ethnography's interpretive nature has been so popular in the field of qualitative evidence synthesis, at least in health research, as we demonstrate below.

\section{The steady growth of published meta-ethnographies in health research}

Since the early 1990s there has been a huge increase in the publication rate of peerreviewed meta-ethnography journal articles in health-related research (Dixon-Woods, Booth, and Sutton 2007; Hannes and Macaitis 2012; France et al. 2014). Dixon-Woods, Booth and Sutton (2007) who reviewed qualitative syntheses published between 1988 and 2004, only counted 42 in total in health care, mostly on nursing topics and published 
in North America. They noted that, of those, $45 \%$ had used meta-ethnography. Their review was updated by Hannes and Macaitis (2012), who found that 82 qualitative syntheses had been published between 2005 and 2008 alone, $30 \%$ of which were metaethnographies. More recently, France et al.'s (2014) methodological systematic review identified 32 meta-ethnographies published in the two years alone between 2012 and 2013, - more than double the average annual publication rate since Hannes and Macaitis' review. Furthermore, a recent, as yet unpublished, systematic review as part of a project to develop a meta-ethnography reporting guideline (France et al. 2015), found 118 metaethnographies published in the two years from 2014 and 2015 alone, which points to a huge growth in the publication rate of health-related meta-ethnographies in the last few years. France et al. (2014) partly attributed this rise in published meta-ethnographies to the fact that, at least in the UK, major funders of published meta-ethnographies exist in the form of the National Institute for Health Research (NIHR) and the National Health Service. However, it is important to note that many authors of meta-ethnographies seem to use the label 'meta-ethnography' without actually following the principles of the approach (France et al. 2014; Hannes and Macaitis 2012), as we discuss in further sections reflecting on the conduct and reporting of meta-ethnographies.

In order to chart how meta-ethnography has been used and has evolved over time, we now look back at some of the earliest published examples in health-related research. The first health researchers to adopt the approach worked in nursing research. One of the earliest examples is published in the journal Qualitative Health Research by Jensen and Allen (1994), two academic nurses based at the University of Alberta in Canada. The authors' aim, considered well-suited to a meta-ethnographic approach, was to develop an inductive theory on wellness and illness, which they indeed achieved. They did not justify why they chose meta-ethnography as a methodology, despite its relative novelty as an approach at 
the time. They included a much larger number of studies than the three to five Noblit and Hare had synthesised - 112 studies (including journal articles, theses and dissertations), not all of which were ethnographies, a departure from Noblit and Hare's application of the approach.

Four years later, Paterson, Thorne and Dewis (1998) also academic nurses in British Columbia, Canada, published in the Journal of Nursing Scholarship a meta-ethnography to advance understanding of the lived experience of diabetes. They developed a metaphor to explain the experience of adapting to and managing diabetes. They purposefully considered disconfirming cases from the studies and tested conflicting hypotheses, which makes their meta-ethnography one of the first, and rare, examples of refutational translation. They synthesised 43 different studies (also many more studies than Noblit and Hare had synthesised) identified by an electronic search; at the time Noblit and Hare wrote their book on meta-ethnography, electronic bibliographic databases did not exist, so this search strategy, permitted by technological advance, was an adaptation of the approach.

Subsequently, in the early to mid-2000s a group of predominantly social scientists based in the United Kingdom published, as part of a methodological study funded by Health Technology Assessment (Britten et al. 2002; Campbell et al. 2003; Pound et al. 2005), three meta-ethnographies which today are considered seminal in in qualitative health research. Britten, Campbell, Pope et al (2002) published in the Journal of Health Services Research and Policy, a pilot worked example of a meta-ethnography about the lay meanings of medicines, the aim of which was a methodological study to assess the benefits of meta-ethnography for the synthesis of qualitative research. The worked example included only four arbitrarily chosen studies, of which three written by the 
authors, purposefully selected in order to enable the reviewers "to explore the question of asking the authors of synthesised papers to comment on a synthesis of their work" (210). This worked example is considered seminal because it was fully embedded in the interpretive paradigm, laid out clearly the seven phases of meta-ethnography and the manner in which translation was conducted, and developed a line of argument synthesis accounting for patients' medicine-taking behaviours. Its authors concluded that "meta ethnography achieves more than a traditional literature review [....] it is possible to synthesise papers in a way that is different from a narrative review and which, we believe, produces new insights" (214). Published in Social Science and Medicine the following year, was another of the team's meta-ethnographies, this one focusing on lay experiences of diabetes and diabetes care (Campbell et al. 2003). Again the aim was a methodological assessment of meta-ethnography - this time to examine the feasibility of the approach including a formative evaluation of criteria for assessing the research to be synthesised. The authors used 10 journal articles they had purposively sampled, and assessed the quality of studies using the critical appraisal skills programme (CASP) tool (1998), before conducting the synthesis. They concluded that "this evaluation confirmed that meta-ethnography can lead to a synthesis and extension of qualitative research in a defined field of study. In addition, from it, a practical method of qualitative research assessment evolved" (671). This was significant because it was the first metaethnography in health-related research of which we are aware, to quality appraise studies prior to synthesis, a practice which, although somewhat controversial then, has now become fairly commonplace (France et al. 2014).

Finally in Pound et al.'s (2005) meta-ethnography of medicine taking, the authors searched for articles using systematic review methods, critically appraised studies prior 
to synthesis and included 38 studies. This has been considered an important metaethnography because of the manner in which the authors carried out and reported on the translation process - for instance, by innovating with the translation process by first synthesising articles on the same medicine, and then across medicine groups - . It was also significant because of the novel theory it produced, flowing from a line of argument synthesis. Moreover, the evidence from this particular meta-ethnography informed The National Institute for Health and Care Excellence (NICE) Clinical guideline for medicines adherence, a highly novel occurrence for guidelines which have traditionally favoured inclusion of quantitative evidence.

Part of both Campbell et al. (2003) and Pound et al.'s (2005) methodological contribution to the evolution of the meta-ethnography is in the amount of methodological and analytic detail they provided when reporting on each phase of conducting a meta-ethnography (e.g. providing tables to give details of the contexts and concepts of the synthesised studies). They also gave visual representations of the models or lines of argument they developed, and set out to produce interpretive theories of particular health phenomena. The three meta-ethnographies presented above have been highly influential in the use of meta-ethnography in health research and have since been incorporated into, and their methodological work extended, in a HTA report in 2011 for the National Institute for Health Research in the UK (Campbell et al. 2011), thus amounting to the most substantial methodological work on the meta-ethnography approach since the publication of Noblit and Hare's book.

The above sections have shown how the meta-ethnography approach has steadily rose to the fore, and evolved in the field of heath research. The below sections in turn, offer a 
counterpoint from the world of education research, where the approach originated, but where its growth was somewhat delayed.

\section{What then of the delayed growth of meta-ethnography in educational research?}

We stated at the start of this article that over the past few decades meta-ethnography appears to have been used to a lesser extent in educational research than in health research, even though that is where it has its roots (Thorne et al. 2004). In fact, in education, meta-ethnography is only now coming into its own (as this special issue attests). It is not clear why meta-ethnography has been less popular in that field, other than there were several developments that were consuming the energies of qualitative researchers in education at the time when the approach took off in health research.

First, qualitative research in education by the late 1980s was in the process of elaborating a range of approaches to qualitative research, or what Guba and Lincoln termed the “competing paradigms of qualitative research" (Guba and Lincoln 1994, 105): positivism, post positivism, critical theory and constructivism. In education, the critical turn, in particular, was especially compelling and pushed against notions of utilitarianism in which research synthesis in general was implicated. Second, the 'culture wars' over reading instruction, the value of literature and social studies (and now even science) meant that educational policy and practice had been politicized, and qualitative research was often positioned in opposition to efforts to force schools to comply uniformly with state required educational reforms (Noblit and Pink 1987). This politicization of education has meant that educational researchers, regardless of methodology, are even today tentative in their relation to research or evidence based practice in education. As a 
result, meta-ethnography did not catch on the qualitative researchers in education who were actively elaborating their craft while fighting both paradigm wars and culture wars. Finally, neither Noblit nor Hare began a research program around meta-ethnography and instead returned to their established programs of research. Had they done so, this may have changed the trajectory of meta-ethnography. The elaboration of qualitative approaches, the concerns about utilitarianism, and the politicization of educational research took their toll on meta-ethnography but did not impede the expansion in use of qualitative methods in education and other disciplines. New book series and journals, including this one, have been responses to this expansion of use. Shortly after the new millennium, articles began to appear that commented upon, used and adapted metaethnography. Davies (2000) reviewed various research synthesis approaches and aligned synthesis with assessing the "effectiveness of educational policy and practice" (366), while noting that in the UK there was considerable interest in research synthesis, including the then recent establishment of the Campbell Collaboration for applied social science that paralleled the Cochrane Collaboration for health, as mentioned above. He noted that the elaboration of qualitative approaches had resulted in a heterogeneity of qualitative approaches and theoretical perspectives which "may be greater with qualitative research" (371). He also noted that the applicability of syntheses was more limited given that classrooms vary year to year and are complex social organizations. “Teachers, learners, parents, and educational managers tend to have particular and context-specific concerns about education..." (374) which has to be integrated with evidence. Here Davies acknowledges the utilitarian pressure on research and synthesis while complicating the same relationship. 
Rice (2002), soon after, used meta-ethnography to synthesize studies about Professional Learning Communities' collaboration process. Case studies of the collaboration process were synthesized to yield twelve themes organized under four categories. Situational factors included the unwillingness to collaborate, prior relationships and attitudes, and the difficulty in obtaining sustaining funding. Structural dimensions included the lack of formalization, issues of parity and control, and the importance of the principal. The main process dimension involved miscommunication, while the relational dimension included inter-organizational strain, conflicting goals between organizations, initial distrust and scepticism, the importance of key individuals, and the importance of informal meetings. The study resulted in a set of practical recommendations and the line of argument that it was the relations dimension that captured most of the issues in collaboration. This study re-categorized the extant themes in the studies but did not offer interpretations at a new level or in a different vein.

Doyle (2003) contributed to the evolution of the approach with a meta-ethnographic study for methodological purposes, finding limitations in the approach and suggesting enhancements which included explaining how the author of the meta-ethnography is situated in the study and text, moving to an augmented grounded theory approach, employing the language of the authors of the original studies in the translation, theorizing how the studies relate, providing audit trails, and member checks. Substantively, her meta-ethnography of educational leadership yielded three patterns: "commitment to a vision, power with an essence, and congruency of actions" (338). She also sees in metaethnography the "possibility to empower" by "amplifying voices", "facilitating praxis" (339), weakening "hierarchical roles", and extending "borders", "to communicate across groups" including disciplinary groups (340). Rice and Doyle both created syntheses that were rather close to the studies synthesized. Doyle did push the methodology in novel 
ways, including incorporating the synthesizer's positionality into the text, and enabled it to have wider implications in the politics of knowledge that surround education.

Savin-Baden and her colleagues later in the decade published two articles on higher education that emphasized meta-ethnography as an interpretive endeavour, and signalled a push to return to Noblit and Hare's idea that synthesis could be more than what the original studies contained. Most importantly, they also incorporated the synthesizers' positionality into the texts, were critical in orientation, and importantly problematized the pursuit of similarity over difference in meta-ethnographies. Savin-Baden and Major (2007) used interpretive meta-ethnography to examine how innovative approaches to learning influence the understandings faculty have of their teaching, using ProblemBased Learning in higher education as the case in point. In an interpretive approach they argued that their interpretive stance needed to be explicit and that this same stance led to data being reinterpreted as part of the synthesis. Also in standing against conventional notions of validity in qualitative research, they engaged with four "honesties": "situating ourselves in relation to our participants"; "voicing our mistakes"; "situating ourselves in relation to the data"; and "taking a critical stance towards research" (837). Unlike earlier authors in education, they were explicit about using synthesis to develop second order interpretation and then worked to develop third order interpretations that went beyond a summary of the findings of the original studies. Four overarching themes developed: Changes in role perception (e.g. moving from lecturer to facilitator); Changes in perspectives about the nature of authority and control (repositioning to maintain control, to offer control and to relinquish control); Shifts in views about the nature of disciplinary knowledge (e.g. perceiving disciplines in novel ways, breaking down artificial boundaries within the discipline and across disciplinary lines); and Changes in perception about the 
nature of teaching and learning (teaching for understanding, as shared practice, and as research). They concluded: "what the synthesis added was the importance of facilitating change in academic identities and in confronting issues of power and control ...." (850). Savin-Baden, McFarland and Savin-Baden (2008) in another interpretive metaethnography of learning and teaching in higher education examined the relationship across practice, transfer and community. They explicitly focused on literature that problematized and clarified the relations between the three main concepts; literature that explored different practitioner, policy and development understandings and the tensions evident among them; areas where existing knowledge is not being used, and locating needed further research. Again the interpretive meta-ethnography developed the original author's interpretations, pushing beyond what the original studies found, to offer novel interpretations. In the end, the meta-ethnography revealed that "issues of pedagogical stance, disjunction, learning spaces, agency, notions of improvement and communities of interest all help to locate the overarching themes and hidden subtexts that are strong influences on areas of practice, transfer and community" (225). For meta-ethnography, this was important, as it raised the issue that although interpretive meta-ethnographies allows a new interpretation to be constructed:

the difficulty with this approach is that there is a tendency to privilege similarity (and sometimes difference) because the process of sense making across studies tends to focus on ordering and cohesion rather than exploring conflicting data sets and contestable positions (225).

Interestingly, this issue has also been raised regarding QES by health researchers (Booth et al 2013). However this idea to focus on difference, positionality and critique was not picked up in all of the later meta-ethnographic studies in education. For example, Tondeur et al (2012) used meta-ethnography to study strategies to prepare pre-service teachers to 
integrate technology into instruction. The focus was on the content and delivery methods which best prepare pre-service teachers for effective technology integration. The key themes were seen as linked and difficult to address separately, but were also rather close to those in the individual studies and framed similarly in terms of promoting technology integration without positionality or critique being evident. While also not picking up on positionality and critique, Jamal et al (2013) conducted a systematic review and metaethnography of school environment and student health that found considerable complexity and led to a reconsideration of theory as well. Four 'meta-themes' (4) resulted in a line of argument that: 1. Aggressive behaviour and substance use are elements of status and social relations in adolescents; 2 . Problematic health behaviours were evident in unsupervised 'hotspots' (6) of the school; 3. Good relationships with teachers are important but school organization and policies are constraints for these; and 4. Unhappiness in school lead students to 'escape' (7) school in unauthorized ways.

This focus on theory as well as positionality, critique and difference can be found in Beach et al (2014). They synthesized a set of studies of teacher education in Sweden that addressed two competing historical policy tendencies: 1 . unification of the profession with a professional and research based knowledge base; and 2. a return to a more dualist, age and grade based professionalism. Theoretically they also were demonstrating the value of Bernstein's theories (cf. Bernstein 2003) in understanding how teacher education is situated in social and political processes and institutions. Their goal was to identify paths of thought that were not as evident in the original studies (and which they had conducted independently). The meta-ethnography revealed that the unification oriented policies had not been very successful in influencing either practice or teacher professional perspectives. Thus the return to dualist policy was a misnomer as unification policies had never been substantiated in practice. They concluded that education policy is more 
ideological than based in scientific evidence, raising questions about the wisdom of government interventions in teacher education. In this study, the politicized nature of education and research, a critique of utilitarian approaches to policy and practice, an elaboration of the meta-ethnographic approach, the synthesizers' place in the text, and an explicit focus on theory are all full blown. A very recent study holds some parallel with Beach et al (2014), in speaking against a policy domain. Baker and Harter (2015) decided, in their meta-ethnography, to revisit the case studies that undergirded the development of cognitively guided instruction (CGI) in elementary mathematics instruction because of a high profile critique of the differentiated instruction (which they argued was a "working model of differentiation" (27). In their meta-ethnography they specified their positionality and perspective, addressed a key theory of educational practice and engaged the high profile critique that had been recently been lodged. They focused on 6 case studies that "exemplified teachers' voices around CGI" (29). The discerned three themes of student-centred pacing, alternative forms of assessment, and teacher scaffolding. They then used these themes to reanalyse CGI as "a metaphor of differentiation" which had been critiqued as essentially impossible to implement. They then used a reciprocal translation of the critic's characterization of differentiation and showed that in each element of the critiques the synthesis showed that teachers were able to effectively achieve what the critic had denied as possible. This meta-ethnography then elaborates the use meta-ethnography to speak to debates about educational practice. The authors are explicit about that in this case CGI is a living metaphor for the more abstract concept of differentiation - but one that speaks of possibility that others deny.

Another trend of interest to the authors of this article, which transcends both the fields of health and education, is the increasing number of meta-ethnographies published since 
2010 in the field of health education (particularly nursing education). For instance, we mention here two interesting and recent articles concerning meta-ethnography in health professions and medical education. Bearman and Dawson (2013) wrote a review of qualitative synthesis approaches for health professions education. They review thematic analysis (redefining findings into key themes), meta-ethnography (adding a new level of interpretation) and realist review (using explanatory theories as the framework for the review) methodologies. In their conceptualization, meta-ethnography emphasizes knowledge as subjective and tends toward developing theories over summarization. Using Savin-Baden and Major's 2007 study commented upon above as an example of meta-ethnography, they noted that the synthesis "findings provide a deeper understanding of the phenomenon rather than being overly concerned with effectiveness" ( 257$)$. Further, they noted that all three synthesis approaches "created value and meaning" (258). From these, Bearman and Dawson(2013) make some general points. In particular, they note that the idea of rigour in qualitative synthesis may be viewed as problematic by some, and come done on the side of transparency of process of synthesis over reproducibility. To this end, they argue that for three criteria of rigour in qualitative synthesis: researchers' stance, transparency of synthesis process, and triangulation of multiple perspectives (of the research team and others). While all three are well-taken, they all emerge from SavinBaden and Major's higher education meta-ethnography.

Park et al (2015), on the other hand, conducted a systematic review of undergraduate medical education in the UK, concerning the use of the general practice setting. The quantitative results found, among other things, that the general practice setting was as good as or better than the hospital setting with the drawback of lower reports of relational empathy by patients when a student was present. The qualitative meta-ethnography led to two general themes: interpersonal interactions for learning and socio-cultural spaces 
for learning. The former suggested that the practice setting was a community that had benefits for emotional support and practical learning. The latter suggested that general practice and the hospital are distinct learning contexts that lead students to attempt to integrate the learning and knowledge from both cultures. While this synthesis may be better understood in the traditions and trajectories of studies in the health fields than in regards to the review of education meta-ethnographies above, it does, however, provide evidence that education is a complex and contextual endeavour that requires humans to construct resolutions of difference on their own rather than the resolution being systemically determined.

For Education research, then, the above has shown that meta-ethnography has been the least useful when it recapitulated what the original studies had to say, by either recategorizing it or by endeavouring to assert that this is 'what is known'. Both of these endeavours, of course, can be of interest, but they add little to knowledge, and little in the way of new interpretations. Meta-ethnography is at its most useful when it addresses the contexts and nature of educational knowledge, when the synthesizers' positionality is actively engaged in the text, when complexity and difference are sought out, and when theory and the history of ideas in an area of research are addressed. In doing so, metaethnography gives education another way to consider, critique and advance ideas, research methods, and the field as an intellectual endeavour. It challenges educational researchers to take responsibility for that which they assumes was outside their domain of action. 


\section{Conclusion}

As this article attests, meta-ethnography has been extensively used in health research in the past decade but has remained all too rare an occasion in Education. However the above shows that lessons can be learnt from both fields, for the conduct of meta-ethnography in any discipline. First, it is important to realize that the interest in synthesis is not just a natural occurrence but one that is situated in the history of qualitative research in any given field. Secondly, that research itself has become increasingly politicized, and this has often led to an effort for research to serve practical and policy interests. Admittedly, research aims to lead to improvements in the human condition, but if Education is any lesson here, there is a problematic reductionism that can result from such endeavours and an underlying ideological context that needs to be addressed first. Critique and a thorough analytical work can be an antidotes to these forces. Thirdly, synthesis attempts such as meta-ethnography can all too easily stay close to the original studies and therefore add little to knowledge ( as this has been seen to be the case when in some of the studies mentioned above when they are designed primarily to improve practice).Fourth, and to conclude, meta-ethnography has added the most to education and health knowledge when: 1 it is explicitly interpretive and seeks to develop novel conceptualizations; 2. when it seeks out difference rather than assumes similarity or cohesion of ideas and practices; 3 . When it invokes and speaks to theory; 4 . When it addresses and critiques the relative politicization of policy, practice, research and theory; and 5. When it conceptualizes human action in its relevant contexts-- with the complexity and contradictions which impact upon and prompt human agency. 


\section{Acknowledgements}

We would like to acknowledge the contribution of our colleagues in the eMERGe Project team who are currently working on developing a Meta-ethnography reporting guideline (http://emergeproject.org/) to our reflections on the evolution of the meta-ethnography approach in health research:Jane Noyes, Margaret Maxwell, Nicola Ring, Ruth Jepson, Edward Duncan, Ruth Turley, Rachel Roberts and Derek Jones.

\section{References}

Andrews, R. 2005. "The place of systematic reviews in education research." Review of. British Journal of Educational Studies 53 (4):399-416.

Baker, K. and M. Harter. 2015. "A living metaphor of differentiation: A metaethnography of cognitively guided instruction in the elementary classroom". Journal of mathematics education at Teachers College. 6:2:27-36.

Beach, D., C. Bagley, A. Erikson, and C. Player-Koro (2014). "Changing teacher education in Sweden: using meta-ethnographic analysis to understand and describe policymaking and educational changes". Teaching and Teacher Education.44: 160-167.

Bearman, M. and P. Dawson. 2013. "Qualitative synthesis and systematic review in health professions education". Medical education 47 (3): 252-260.

Bernstein, B. (2003). Class, codes and control. Vol. 4. The structuring of pedagogic discourse. London: Routledge.

Booth, A. 2001. "Cochrane or cock-eyed? How should we conduct systematic reviews of qualitative research?" Paper presented at the Qualitative Evidence-based Practice Conference, Taking a Critical Stance. Coventry University, May 14-16 2001 
Booth, A., C. Carroll, I. Ilott, L.L. Low, and K. Cooper."Desperately seeking dissonance: identifying the disconfirming case in qualitative evidence synthesis". Qualitative Health Research 23 (1) :126-141.

Britten, N., R. Campbell, C. Pope, J. Donovan, M. Morgan, and R. Pill. 2002. "Using meta ethnography to synthesise qualitative research: a worked example". Journal of Health Services \& Research Policy 7 (4): 209-15.

Campbell, R., P. Pound, M. Morgan, G. Daker-White, N. Britten, R. Pill, L. Yardley, C. Pope, and J. Donovan. 2011. "Evaluating meta-ethnography: systematic analysis and synthesis of qualitative research." Health Technology Assessment 15 (43): 1164.

Campbell, R., P. Pound, C. Pope, N. Britten, R. Pill, M. Morgan, and J. Donovan. 2003. "Evaluating meta-ethnography: a synthesis of qualitative research on lay experiences of diabetes and diabetes care." Social Science \& Medicine 56 (4):67184.

CASP Critical Appraisal Skills. 1998. 'Critical Appraisal Skills Programme' (CASP)

Chalmers, I. 1993. "The Cochrane collaboration: preparing, maintaining, and disseminating systematic reviews of the effects of health care." Annals of the New York Academy of Sciences 703:156-63.

Cochrane, A.L. 1972 Effectiveness and Efficiency. Random Reflections on Health Services: London: Nuffield Provincial Hospitals Trust.

Davies, P. 2000. "The relevance of systematic reviews to educational policy and practice." Oxford Review of Education 26 (3-4): 365-378.

Dixon-Woods, M., S. Bonas, A. Booth, D.R. Jones, T. Miller, A. J. Sutton, R. L. Shaw, J.A. Smith, and B. Young. 2006. "How Can Systematic Reviews Incorporate Qualitative Research? A Critical Perspective." Qualitative research 6 (1):27-44. 
Dixon-Woods, M., A. Booth, and A. J. Sutton. 2007. "Synthesizing qualitative research: a review of published reports." Qualitative research 7 (3):375-422.

Doyle, L. 2003. "Synthesis through Meta-Ethnography: Paradoxes, Enhancements, and Possibilities". Qualitative Research 3 (3): 321-344 .

Evans, J., and P. Benefield. 2001. "Systematic Reviews of Educational Research: does the medical model fit?" Review of. British Educational Research Journal 27 (5).

Finfgeld-Connett, D., and E. D. Johnson. 2013. "Literature search strategies for conducting knowledge-building and theory-generating qualitative systematic reviews." Journal of Advanced Nursing 69 (1):194-204.

Finfgeld, D.L. 1999. "Courage as a Process of Pushing Beyond the Struggle." Qualitative Health Research 9 (6):803-14.

France, E. F., N. Ring, J. Noyes, M. Maxwell, R. Jepson, E. Duncan, R. Turley, D. Jones, and I. Uny. 2015. "Protocol-developing meta-ethnography reporting guidelines (eMERGe)." BMC Medical Research Methodololy 15 (1):103.

France, E. F., N. Ring, R. Thomas, J. Noyes, M. Maxwell, and R. Jepson. 2014. "A methodological systematic review of what's wrong with meta-ethnography reporting." BMC Medical Research Methodololy 14 (1):119.

Guba, E., and Y. Lincoln 1994. "Competing paradigms of qualitative research". In N. Denzin and Y. Lincoln (Eds.) Handbook of qualitative research methods. Thousand Oaks CA: Sage. 105-117.

Hannes, K., and K. Macaitis. 2012. "A move to more systematic and transparent approaches in qualitative evidence synthesis: update on a review of published papers." Qualitative research 12 (4):402-42. 
Jamal, F., A. Fletcher, A. Harden, H.Wells, J. Thomas, and C.Bonell .2013. "The school environment and student health: a systematic review and meta-ethnography of qualitative research." BMC Public Health 13(1), 798.

Jensen, L. A., and M. N. Allen. 1994. "A Synthesis of Qualitative Research on WellnessIllness." Qualitative Health Research 4 (4):349-69.

Noblit, G., and D. Hare. 1988. Meta-Ethnography: Synthesiszing Qualitative Studies. Vol. 11. California: Sage Publications.

Noblit, G.and W. Pink (eds.).1987. Schooling in Social Context: Qualitative Studies. Norwood, NJ: Ablex Publishing Corporation.

Page, S., and J. Keady. 2010. "Sharing stories: a meta-ethnographic analysis of 12 autobiographies written by people with dementia between 1989 and 2007." Review of Ageing \& Society 30:511-26.

Park, S., N. F. Khan, M. Hampshire, R. Knox, A.Malpass, J. Thomas, B. Anagnostellis et al. "A BEME systematic review of UK undergraduate medical education in the general practice setting: BEME Guide No. 32". Medical teacher 37(7): 611-630.

Paterson, B. L. 2011. "'It looks great but how do I know if it fits?': an introduction to meta-synthesis research." In Synthesizing qualitative research: choosing the right approach, edited by K. Hannes and C. Lockwood, 1-20. Wiley-Blackwell BMJ Books.

Paterson, B. L., S. Thorne, and M. Dewis. 1998. "Adapting to and managing diabetes." Image - the Journal of Nursing Scholarship 30:57-62.

Pound, P., N. Britten, M. Morgan, L. Yardley, C. Pope, G. Daker-White, and R. Campbell. 2005. "Resisting medicines: a synthesis of qualitative studies of medicine taking." Social Science \& Medicine 61 (1):133-55. 
Rice, E. H. 2002. "The collaboration process in professional development schools results of a meta-ethnography, 1990-1998." Journal of Teacher Education 53(1): 55-67.

Savin-Baden, M., and C. H. Major. 2007. "Using interpretative meta-ethnography to explore the relationship between innovative approaches to learning and their influence on faculty understanding of teaching." Higher Education 54(6): 833852.

Savin-Baden, M., L. McFarland, and J. Savin-Baden. 2008. "Learning spaces, agency and notions of improvement: What influences thinking and practices about teaching and learning in higher education? An interpretive meta-ethnography". London Review of Education 6 (3): 211-227.

Soundy, A., B. Smith, H. Dawes, H. Pall, K. Gimbrere, and J. Ramsay. 2013. "Patient's expression of hope and illness narratives in three neurological conditions: a metaethnography." Health Psychology Review 7 (2):177-201.

Thorne, S. E. 2015. "Qualitative metasynthesis: a technical exercise or a source of new knowledge?" Psychooncology. 24 (11):1347-8.

Thorne, S., L. Jensen, M. H. Kearney, G. Noblit, and M. Sandelowski. 2004. "Qualitative metasynthesis: Reflections on methodological orientation and ideological agenda." Qualitative Health Research 14:1342-65.

Tondeur, J., J.van Braak, G.Sang, J. Voogt, P. Fisser, and A. Ottenbreit-Leftwich, 2012. "Preparing pre-service teachers to integrate technology in education: A synthesis of qualitative evidence." Computers \& Education 59(1):134-144.

Van Klaveren C., and I. De Wolf. 2013. "Systematic Reviews In Education Research: When Do Effect Studies Provide Evidence?." Tier Working Paper Series Tier WP $13 / 02$ 
Volmink, J., N. Siegfried, K. Robertson, and A. M. Gülmezoglu. 2004. "Research synthesis and dissemination as a bridge to knowledge management: the Cochrane Collaboration." Bulletin of the World Health Organization 82 (10):778-83. 